\title{
Relatively Immediate Relaxant Effects of Cholera Toxin on Isolated Rabbit Blood Vessels
}

\author{
Hiromichi Tsuru, Shuji TsujIYAma and Masashi Sasa \\ Department of Pharmacology Hiroshima University School of Medicine \\ Kasumi, Minami-ku, Hiroshima 734, Japan
}

\begin{abstract}
A study was made on the relatively immediate relaxant effect of cholera toxin (CTX) on the isolated ear artery, thoracic aorta and saphenous vein of the rabbit. Both preparations of CTX, containing sodium azide $\left(\mathrm{NaN}_{3}\right)$ and azide-free, showed no effect on the nonprecontracted artery, but CTX containing $\mathrm{NaN}_{3}$ relaxed the moderately precontracted blood vessels with methoxamine promptly, i.e., with a time course of min order. However, the immediate relaxation produced by CTX containing $\mathrm{NaN}_{3}$ was attributed mainly to $\mathrm{NaN}_{3}$. Azide-free CTX, on the other hand, at $1-10 \mu \mathrm{g} / \mathrm{ml}$ gradually produced concentration-dependent relaxation of the precontracted vessels. The relaxant effects of CTX on the vessels were slow and long-lasting, i.e., with a time course of $10 \mathrm{~min}$ order. The relaxation induced by CTX was not influenced by the removal of endothelium nor by pretreatment with $10 \mu \mathrm{M}$ indomethacin, $3 \mu \mathrm{M}$ atropine or $3 \mu \mathrm{M}$ propranolol. Activation of protein kinase $\mathrm{C}$ by a phorbol ester inhibited the relaxant effect of CTX. These results indicate that CTX relaxes the blood vessels by directly acting on the smooth muscles, without mediation by known endogenous relaxing factor, such as endothelium-derived relaxing factor $(\mathrm{EDRF}=$ NO) or prostaglandin $I_{2}$ (prostacyclin) and by muscarinic receptor or $\beta$-adrenoceptor.
\end{abstract}

Key words : cholera toxin, isolated blood vessels, vasorelaxation, sodium azide.

\section{Introduction}

Cholera toxin (CTX) and sodium fluoride $(\mathrm{NaF})$ have often been used as tools to analyze the intracellular signal transduction, because they increase the cellular cyclic AMP level by activating the stimulatory GTP-binding regulatory protein (Gs) coupled to adenylate cyclase (Rall and Sutherland, 1955 ; Birnbaumer et al., 1985). In the course of study on the vascular $\beta$-adrenoceptor responses, we found that $\mathrm{NaF}$ relaxes the blood vessels by releasing endothelium-derived relaxing factor $(\mathrm{EDRF}=\mathrm{NO})$ and contracts the endothelium-removed vessels (Cushing et al., 1990; Tsuru, 1991). Thus, NaF does not seem suitable for study on the relaxant response mediated by Gs-adenylate cyclase system in the blood vessel.

CTX, on the other hand, has been shown to produce a slow-onset and long-lived inhibition of the contractile responses to $\alpha$-adrenoceptor stimulation by increasing the cyclic AMP level in some arteries (Ousterhout and Steinsland, 1981 ; Asano et al., 1988). However, there seems no report showing that CTX produces direct relaxation of contracted blood vessels. The 
present study was undertaken to characterize the relatively immediate relaxant effect of CTX on the rabbit blood vessels. The following attentions were especially paid in the present experiment: (1) How much did $\mathrm{NaN}_{3}$, which was contained in a CTX preparation, participate in the response to CTX with $\mathrm{NaN}_{3}$ ? Asano and coworkers (1988) have observed unexpectedly potent antagonism of the response to norepinephrine (NE) after application of $1 \mu \mathrm{g} / \mathrm{ml} \mathrm{CTX}$ for only $10 \mathrm{~min}$. Because the reconstituted stock solution of CTX used contained $\mathrm{NaN}_{3}$, the antagonism observed was likely due to the effect of $\mathrm{NaN}_{3}$ rather than CTX. Accordingly, they minimized with much effort, the effect of $\mathrm{NaN}_{3}$ on the responses to $\mathrm{NE}$ by repeated washing.

(2) Whether CTX action was mediated by prostanoid production or not? Because it has been found that CTX not only enhances prostaglandin $\mathrm{E}_{2}$ synthesis markedly in a murine macrophage cell line (Burch et al., 1988), but also amplifies prostacyclin synthesis in bovine aortic smooth muscle cells (Demolle and Boeynaems, 1989). (3) In addition, what was the effect of phorbol ester on the CTX-induced vasorelaxation? Because the activation of protein kinase $\mathrm{C}$ by phorbol ester has been shown to have a variety of effects on hormone-sensitive adenylate cyclase activity (Heyworth et al., 1984 ; Bozou et al., 1987).

\section{Materials and Methods}

This study was approved by the Animal Welfare Committee of Hiroshima University School of Medicine.

Male Japanese White rabbits, weighing 2-3 kg, were anesthetized with pentobarbital sodium $35 \mathrm{mg} / \mathrm{kg}$, i.v. and exsanguinated from the common carotid artery. The ear artery, thoracic aorta and saphenous vein were dissected and placed in the chilled Krebs' bicarbonate solution. The composition of the solution (in $\mathrm{mM}$ ) was: $\mathrm{NaCl} 119, \mathrm{KCl} 4.7, \mathrm{CaCl}_{2} 2.5, \mathrm{KH}_{2} \mathrm{PO}_{4}$ 1.2, $\mathrm{MgSO}_{4} 1.2, \mathrm{NaHCO}_{3} 25.0$ and glucose 11.1. The solution was previously aerated with a gas mixture of $95 \% \mathrm{O}_{2}$ and $5 \% \mathrm{CO}_{2}$.

Isolated blood vessel segments were cleaned of connective tissue under a dissecting microscope and made into ring preparations of $2 \mathrm{~mm}$ long for the thoracic aorta and $4 \mathrm{~mm}$ long for the ear artery and saphenous vein. In some preparations, the endothelium was rubbed gently using a thin wooden stick and the absence of endothelium was confirmed by the lack of acetylcholine or calcium ionophore A23187-induced relaxation (Tsuru, 1991). Each preparation was suspended in a tissue bath of $10 \mathrm{ml}$ which contained Krebs' solution aerated with the gas mixture and maintained at $37^{\circ} \mathrm{C}$ as described previously (Tsuru et al., 1990). The preparation was given an optimum load of $2 \mathrm{~g}$ in the artery and $0.3 \mathrm{~g}$ in the vein, and equilibrated for $1.5 \mathrm{hr}$ before starting experiments. During the equilibration period, the bath solution was renewed every 15-20 min. Isometric tension was recorded on an ink-writing oscillograph (Nihon Kohden Kogyo, Tokyo, Japan, model WI-641G) via force-displacement transducers (Nihon Kohden Kogyo, Tokyo, Japan, model TB-611T).

Relaxation responses of blood vessels were examined after moderate contraction with 0.1 $1 \mu \mathrm{M}$ of $\mathrm{NE}$ or methoxamine, which produced $25-60 \%$ of $\mathrm{NE}$-induced maximum contractions, to observe relaxation responses clearly. The maximum relaxation of each preparation was obtained by addition of $100 \mu \mathrm{M}$ papaverine at the end of experiment.

Two kinds of CTX preparations, i.e., one containing sodium azide $\left(\mathrm{NaN}_{3}\right)$ and the other of 
azide-free, were purchased from List Biological Laboratories, Inc. (Campbell, CA, U.S.A.). When a lyophilized powder of the former CTX preparation was reconstituted to $1 \mathrm{ml}$ with distilled water, it contained $1.0 \mathrm{mg}$ of the protein in Tris buffer $\left(50 \mathrm{mM}\right.$ Tris, $1 \mathrm{mM} \mathrm{Na} \mathrm{EDTA}_{2}$, $3 \mathrm{mM} \mathrm{NaN}_{3}$ and $200 \mathrm{mM} \mathrm{NaCl}, \mathrm{pH}$ 7.5). Both the CTX stock solutions, containing $\mathrm{NaN}_{3}$ and azide-free, at this concentration were stored at $4{ }^{\circ} \mathrm{C}$. The vehicle solution containing $50 \mathrm{mM}$ Tris, $1 \mathrm{mM} \mathrm{Na} \mathrm{maDTA}_{2}$ and $200 \mathrm{mM} \mathrm{NaCl}$ was also reconstituted for checking the effect of vehicle. When the action of $\mathrm{NaN}_{3}$ was studied, $\mathrm{NaN}_{3}$ was dissolved with the similar constitution of the vehicle solution.

(-)-Norepinephrine bitartrate, $( \pm)$-propranolol hydrochloride, indomethacin, acetylcholine chloride, atropine sulphate, calcium ionophore A23187, phorbol 12-myristate 13-acetate and $4 \alpha$-phorbol-12, 13-didecanoate were purchased from Sigma Chemical Co. (St. Louis, MO, USA). Papaverine hydrochloride was obtained from Tokyo Kasei (Tokyo, Japan).

Results shown in the text, tables and figures are expressed as the mean \pm S.E.M. obtained from 4 to 6 experiments. Significance of difference between two means was determined by unpaired Student's $t$-test. Differences with $\mathrm{P}$ values less than 0.05 were considered to be statistically significant.

\section{Results}

CTX preparations, one containing $\mathrm{NaN}_{3}$ and the other being azide-free, showed no apparent effect on the non-precontracted blood vessels. Therefore, the relaxant effects of CTX were studied using vessels precontracted moderately with $0.1-1 \mu \mathrm{M}$ of NE or methoxamine, which produced $25-60 \%$ of the NE-induced maximum contraction, so that the relaxant response could be clearly observed (Tsuru et al., 1990).

CTX containing $\mathrm{NaN}_{3}$ relaxed promptly the blood vessels which had been precontracted moderately with NE or methoxamine, i.e., with a time course of min order (Fig. 1A). On the other hand, $\mathrm{NaN}_{3}$, which was dissolved in a similar constituent of CTX preparation except for CTX, relaxed the vessels similarly to CTX with $\mathrm{NaN}_{3}$ (Fig. 1B). Based on the concentration-
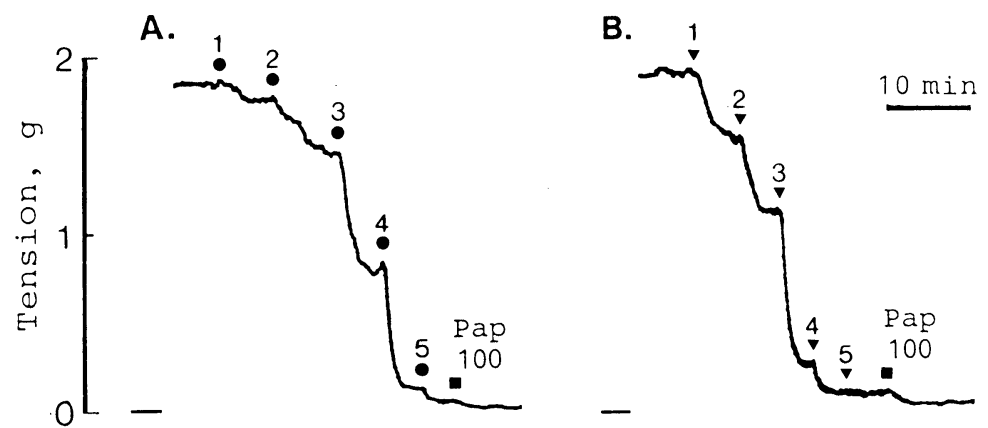

Fig. 1. Representative tracing showing the prompt relaxant responses to cholera toxin (CTX) with $\mathrm{NaN}_{3}(\mathrm{~A})$ and to $\mathrm{NaN}_{3}$ alone (B). Concentrations of $\mathrm{NaN}_{3}(\mu \mathrm{M})$ and CTX $(\mu \mathrm{g} / \mathrm{ml})$ in panel A were as follows. $1: 0.1$ and $0.03 ; 2: 0.3$ and $0.1 ; 3: 1$ and $0.3 ; 4: 3$ and $1 ; 5: 10$ and 3 , respectively. Concentrations of $\mathrm{NaN}_{3}(\mu \mathrm{M})$ in panel $\mathrm{B}$ were as follows. $1: 0.1 ; 2$ : $0.3 ; 3: 1 ; 4: 3 ; 5: 10$, respectively. Thus, the numbers are comparable between panel $\mathrm{A}$ and panel $\mathrm{B}$ regarding concentrations of $\mathrm{NaN}_{3}$. Pap 100 : papaverine $100 \mu \mathrm{M}$. 
response curves for $\mathrm{NaN}_{3}$ with CTX and for $\mathrm{NaN}_{3}$ alone, the $\mathrm{pD}_{2}$ values, negative logarithms of median effective concentration, of $\mathrm{NaN}_{3}$ were obtained as $5.79 \pm 0.14(\mathrm{n}=5)$ in the former and $6.10 \pm 0.17(n=5)$ in the latter, respectively. There was no significant difference between these values, indicating that the effect of CTX with $\mathrm{NaN}_{3}$ is mainly due to $\mathrm{NaN}_{3}$. Therefore, the following experiments were done by using an azide-free CTX preparation.

CTX at $1-10 \mu \mathrm{g} / \mathrm{ml}$ gradually produced concentration-dependent relaxation of the vessels precontracted moderately with NE or methoxamine. The relaxant effects of CTX on the rabbit blood vessels were slow and long-lasting, i.e., with a time course of 10 min order (Fig. 2). The onset of CTX-induced relaxation seemed to be faster in the thoracic aorta and saphenous veins (data not shown) than in the ear artery (compare Fig. 2 and Fig. 5A). The CTX concentration-relaxant response curves in the thoracic aorta were not significantly different between the endothelium-intact and endothelium-rubbed preparations (Fig. 3), indicating that the CTX-induced relaxation was not dependent on the endothelium. As azide-free

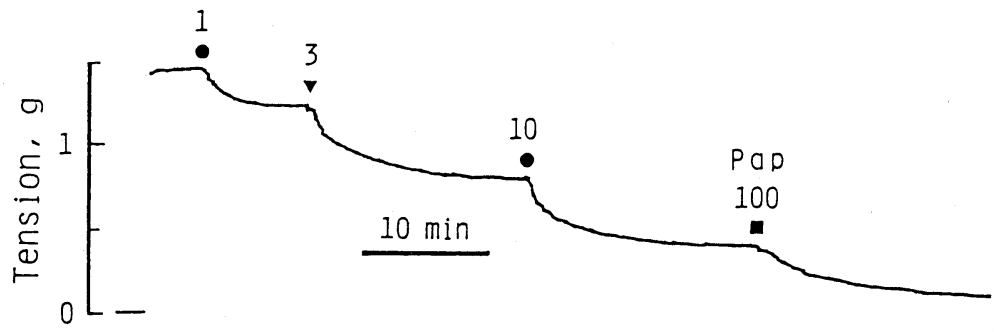

Fig. 2. Typical recording of the relaxant effect of cholera toxin (CTX) in the rabbit thoracic aorta. The preparation was precontracted by methoxamine $0.5 \mu \mathrm{M}$. CTX 1, 3, 10 : cholera toxin 1,3 and $10 \mu \mathrm{g} / \mathrm{ml}$. Pap 100 : papaverine $100 \mu \mathrm{M}$.

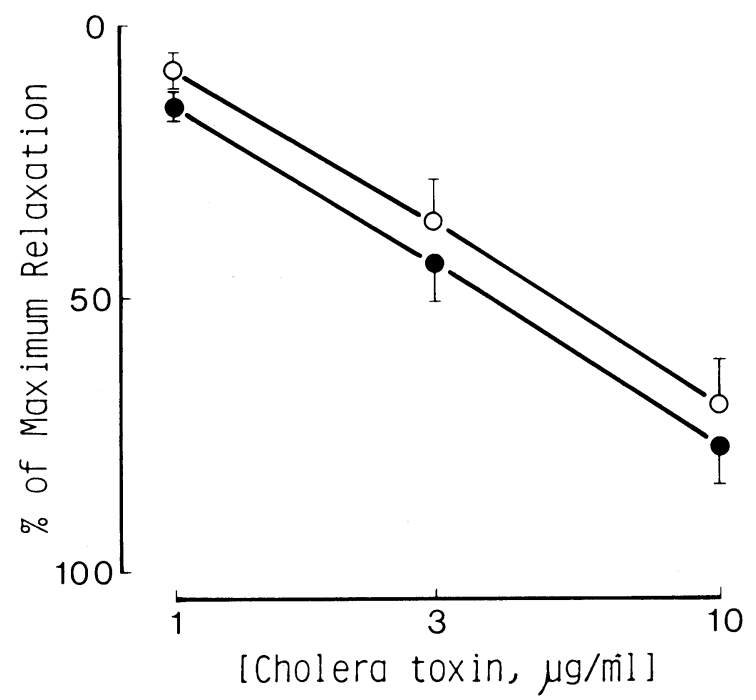

Fig. 3. The concentration-response curve for cholera toxin in the rabbit thoracic aorta. Closed circles, control (endothelium-intact, $n=5$ ). Open circles, endothelium-rubbed preparation $(\mathrm{n}=5)$. Maximum relaxation was obtained by papaverine $100 \mu \mathrm{M}$. 
CTX solution contained a cation chelating agent $\mathrm{Na}_{2}$ EDTA, Tris and $\mathrm{NaCl}$, only small inhibitory responses were observed with an equivalent volume of vehicle. Namely, the relaxation produced by vehicle was less than $10 \%$ of that by CTX with vehicle, being clearly discriminable (data not shown).

The relaxation induced by $5 \mu \mathrm{g} / \mathrm{ml} \mathrm{CTX}$ was not influenced by pretreatment with $10 \mu \mathrm{M}$ indomethacin, $3 \mu \mathrm{M}$ propranolol or $3 \mu \mathrm{M}$ atropine (Fig. 4). The results indicate that CTX relaxes the blood vessels neither by releasing prostanoids nor by activating $\beta$-adrenoceptors and muscarinic receptors.

Phorbol 12-myristate 13-acetate (PMA) $1 \mu \mathrm{M}$ inhibited the relaxant effect of CTX on the artery. In contrast, $4 \alpha$-phorbol-12, 13-didecanoate ( $4 \alpha$-PDD), which is a negative control of PMA, had no influence on the CTX-induced relaxation (Fig. 5). The result indicates that the activation of protein kinase $\mathrm{C}$ by phorbol ester inhibits the relaxant effect of CTX.

A.

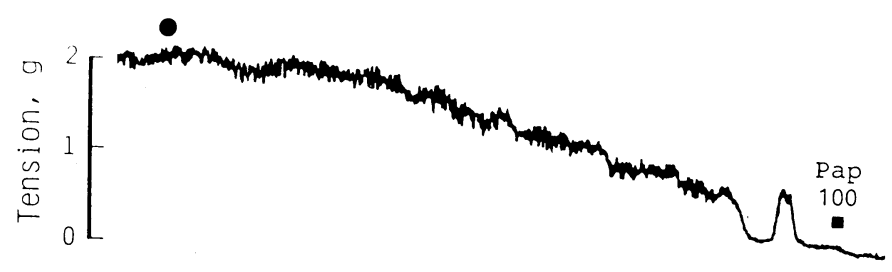

B.

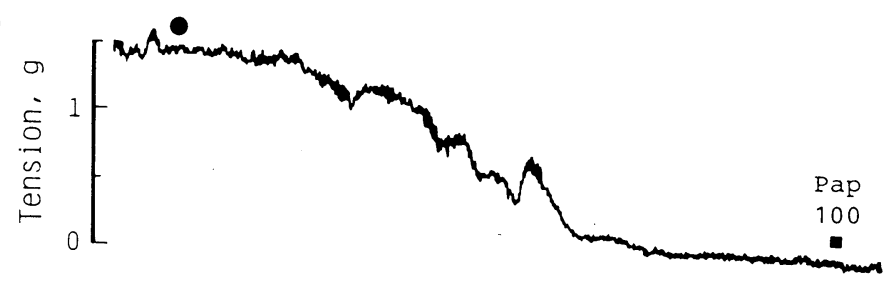

C.

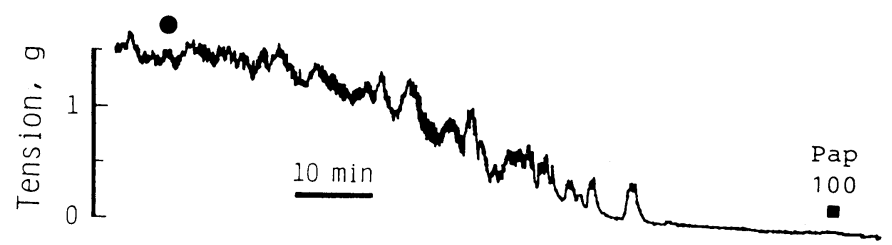

D.

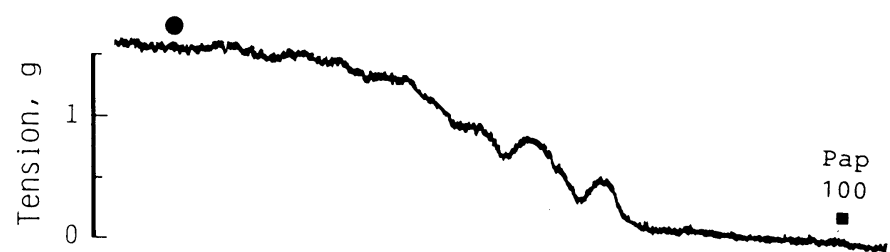

Fig. 4. Effects of atropine, propranolol and indomethacin on the cholera toxin (CTX)-induced relaxation in the ear artery. A. control, $5 \mu \mathrm{g} / \mathrm{ml}$ of CTX alone. B, C and D : pretreated with $3 \mu \mathrm{M}$ atropine, $3 \mu \mathrm{M}$ propranolol and $10 \mu \mathrm{M}$ indomethacin, respectively. These inhibitors were administered $30 \mathrm{~min}$ before CTX. Pap 100 : papaverine $100 \mu \mathrm{M}$. 
A.

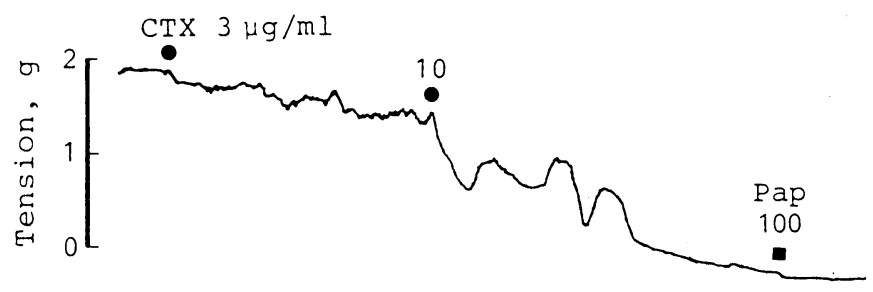

B.

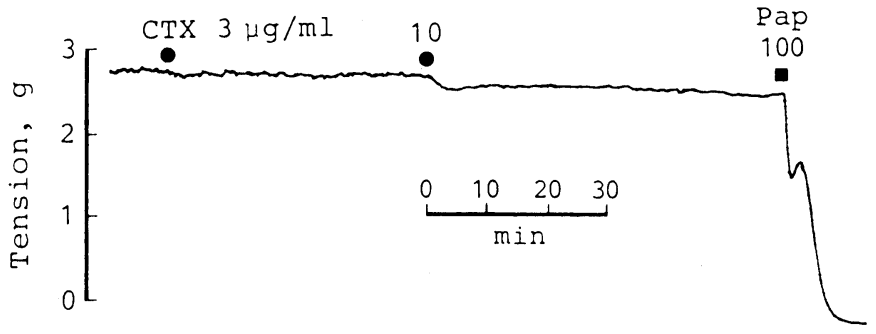

C.

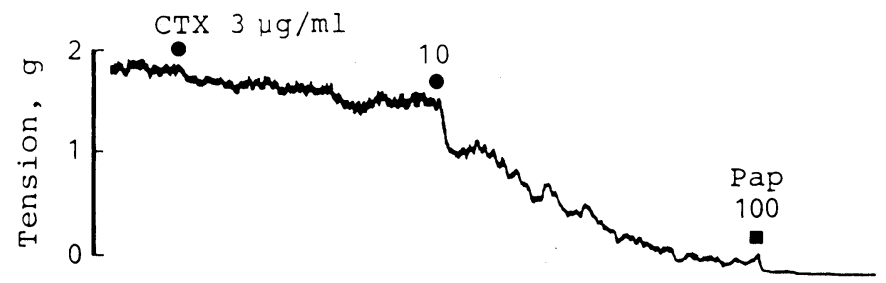

Fig. 5. Inhibition of relaxant response to 3 and $10 \mu \mathrm{g} / \mathrm{ml}$ of cholera toxin (CTX) by activation of protein kinase $\mathrm{C}$ in the rabbit ear artery. $\mathrm{A}$ : control. $\mathrm{B}$ and $\mathrm{C}$ : pretreated with phorbol 12 -myristate 13-acetate (PMA) $1 \mu \mathrm{M}$ and its negative control, $4 \alpha$-phorbol-12,13didecanoate $(4 \alpha-\mathrm{PDD})$, respectively, $30 \mathrm{~min}$ before administration of CTX.

\section{Discussion}

Both NaF and CTX have been extensively used in biochemical analyses of the $\beta$-adrenoceptor-Gs-adenylate cyclase system (Rall and Sutherland, 1958 ; Birnbaumer et al., 1985). The present study, however, revealed that the modes of action of $\mathrm{NaF}$ and CTX on the blood vessels were evidently different. The most important difference is that while the NaF-induced vasorelaxation is dependent on the endothelium (Cushing et al., 1990 ; Tsuru, 1991), the CTXinduced relaxation is not. In addition, though it has been previously shown that $\mathrm{NaF}$ exhibits the complex effects on the blood vessels (Zeng et al., 1989), CTX is more suitable or simpler than $\mathrm{NaF}$ for studying the intracellular signal transduction mechanism of $\beta$-adrenoceptor-Gsadenylate cyclase system in the blood vessels.

When Asano and coworkers (1988) used CTX to examine whether there was reduction of Gs function in the femoral artery of spontaneously hypertensive rats, they were unexpectedly confronted with a problem that the reconstituted stock solution of CTX used contained $\mathrm{NaN}_{3}$, which is known to be a potent activator of guanylate cyclase (Waldman and Murad, 1987). Thus, they had to eliminate the influence of $\mathrm{NaN}_{3}$ on $\alpha$-adrenoceptor-mediated contractions 
with much efforts by repeated washing. In addition, they had to incubate the arterial preparation with $1 \mu \mathrm{g} / \mathrm{ml}$ of CTX for $1 \mathrm{hr}$ to inhibit $\alpha$-adrenoceptor-mediated contractions. The present study reconfirmed potent relaxant effects of $\mathrm{NaN}_{3}$ on the blood vessels. As shown in Fig. 1, the relaxant responses to CTX with $\mathrm{NaN}_{3}$ and to $\mathrm{NaN}_{3}$ alone seemed to be similar on the basis of $\mathrm{NaN}_{3}$ concentration. In fact, the $\mathrm{pD}_{2}$ values for $\mathrm{NaN}_{3}$ calculated from the concentration-response curves for $\mathrm{NaN}_{3}$ with CTX and for $\mathrm{NaN}_{3}$ alone were not different. The symbol number 5 in Fig. $1 \mathrm{~A}$ at which the maximum relaxation was induced referred to 3 $\mu \mathrm{g} / \mathrm{ml} \mathrm{CTX}$ and $10 \mu \mathrm{M} \mathrm{NaN}$. In comparing the time courses of relaxant effect of this and of $3 \mu \mathrm{g} / \mathrm{ml}$ azide-free CTX shown in Fig. $5 \mathrm{~A}$, the notion that the relaxation induced by a mixture of CTX and $\mathrm{NaN}_{3}$ is mainly due to $\mathrm{NaN}_{3}$ is further strengthened. The relaxation induced by $\mathrm{NaN}_{3}$ may be mediated by the increase in level of cyclic GMP as shown by Katsuki and collaborators (1977) in some smooth muscles.

In contrast to the prompt responses to azide-containing CTX, azide-free CTX produced slow-onset and long-lasting relaxation of the blood vessels ; this action was clearly discriminable from that of the vehicle. $\beta$-Adrenoceptors and muscarinic acetylcholine receptors did not seem to be involved in the CTX-induced vasorelaxation because propranolol and atropine had no effect on it (Fig. 5). Also, prostanoids may not be involved in this phenomenon despite the earlier finding that CTX not only enhances prostaglandin $E_{2}$ synthesis markedly in murine macrophage cell line (Burch et al., 1988) but also amplifies prostacyclin synthesis in bovine aortic smooth muscle cells (Demolle and Boeynaems, 1989). The present result that propranolol and indomethacin did not affect the CTX-induced vasorelaxation is consistent with that of Ousterhout and Steinsland (1981). These results indicate that CTX relaxes the blood vessels by directly acting on the smooth muscle cells.

Ousterhout and Steinsland (1981) studied the effects of CTX on the vasoconstriction induced by electrical stimulation of periarterial adrenergic nerves and by exogenously administered NE using the perfusion technique of isolated rabbit ear artery. In this preparation, when CTX was added to the perfusion fluid for 10-20 min, the $\alpha$-adrenoceptor-mediated constriction began to decline after 1 to $2 \mathrm{hr}$ and was gradually inhibited until pressure responses after $10 \mathrm{hr}$ were less than $10 \%$ of those before toxin treatment. In addition, they described that the accumulation of cyclic AMP in arteries exposed to CTX $(4.5-9 \mu \mathrm{g} / \mathrm{ml})$ for $1 \mathrm{hr}$ became evident only after a latent period of 1 to $2 \mathrm{hr}$ and was maintained for at least $6 \mathrm{hr}$. The slow onset and long duration of action of CTX on isolated blood vessels in the present study is consistent qualitatively with the time course of action of the toxin in their experiment (Ousterhout and Steinsland, 1981), but is somewhat different quantitatively. The main difference may be due to the experimental methods employed. Regarding the mechanisms of action of CTX on blood vessels, whereas the increase in cyclic AMP level does not become evident until $2 \mathrm{hr}$ after incubation with CTX in the rabbit ear artery as mentioned above (Ousterhout and Steinsland, 1981), the present study revealed that the relaxant response to CTX appeared within several ten minutes and reached the maximum within 1.5-2 hr after exposure to CTX (Fig. 4). Therefore, further investigation is needed to clarify whether cyclic AMP or some other mechanism is responsible for the relaxant effect of CTX.

PMA $1 \mu \mathrm{M}$ inhibited the relaxant effect of CTX on the artery, whereas $4 \alpha-\mathrm{PDD}$, which is 
a negative control of PMA, had no influence on the CTX-induced relaxation (Fig. 5). The result indicates that the activation of protein kinase $\mathrm{C}$ by phorbol ester inhibited the relaxant effect of CTX. It has been recently reported that phorbol esters, presumably acting via protein kinase C, can have a variety of effects on hormone-sensitive adenylate cyclase. For example, Heyworth and coworkers (1984), on one hand, have suggested that PMA exerts its inhibitory effect on the CTX-stimulated adenylate cyclase activity through the action of protein kinase $\mathrm{C}$ in rat hepatocytes, but on the other hand, Bozou and collaborators (1987) have reported that PMA fails to attenuate the action of CTX to stimulate cyclic AMP production in HT29 cell line which is derived from a human colon adenocarcinoma.

In conclusion, CTX slowly relaxes the isolated blood vessel by directly acting on vascular smooth muscle cells, though the precise action mechanism remains to be resolved.

\section{References}

Asano, M., Masuzawa, K. and Matsuda, T. (1988). Role of stimulatory GTP-binding protein (Gs) in reduced $\beta$-adrenoceptor coupling in the femoral artery of spontaneously hypertensive rats. Brit. J. Pharmacol. 95 : 241-251.

Birnbaumer, L., Codina, J., Mattera, R., Cerione, R.A., Hildebrandt, J.D., Synyer, T., Rojas, F.J., Caron, M.G., Lefkowitz, R.J., and Iyengar, R. (1985). Molecular mechanisms of transmembrane signalling. In: Molecular Aspects of Cellular Regulation, Vol. 4, ed. by P. Cohen and M.D. Houslay, Elsevier, Amsterdam, pp. 131-182.

Bozou, J.-C., Couvineau, A., Rouyer-Fessard, C., Laburthe, M., Vincent, J.-P. and Kitabgi, P. (1987). Phorbol ester induces loss of VIP stimulation of adenylate cyclase and VIP-binding sites in HT29 cells. FEBS Letters $211:$ 151-154.

Burch, D.M., Jelsema, C. and Axelrod, J. (1988). Cholera toxin and pertussis toxin stimulate prostaglandin E synthesis in a murine macrophage cell line. J. Pharmacol. Exp. Ther. 244 : 765-773.

Cushing, D.J., Sabouni, M.H., Brown, G.L. and Mustafa, S.J. (1990). Fluoride produces endotheliumdependent relaxation and endothelium-independent contraction in coronary artery. $J$. Pharmacol. Exp. Ther. 254: 28-32.

Demolle, D. and Boeynaems, J.M. (1989). Cholera and pertussis toxins amplify prostacyclin synthesis in aortic smooth muscle cells. Brit. J. Pharmacol. 98: 717-720.

Heyworth, C.M., Whetton, A.D., Kinsella, A.R. and Houslay, M.D. (1984). The phorbol ester, TPA inhibits glucagon-stimulated adenylate cyclase activity. FEBS Letters 170: 38-42.

Katsuki, S., Arnold, W.P. and Murad, F. (1977). Effects of sodium nitroprusside, nitroglycerin, and sodium azide on levels of cyclic nucleotides and mechanical activity of various tissues. $J$. Cyclic Nucleotide Res 3 : 239-247.

Ousterhout, J.M. and Steinsland, O.S. (1981). Effects of cholera toxin on vasoconstriction and cyclic AMP content of the isolated rabbit ear artery. Life Sci. 28: 2687-2695.

Rall, T.W. and Sutherland, E.W. (1958). Formation of a cyclic adenine ribonucleotide by tissue particles. J. Biol. Chem. 232 : 1065-1076.

Tsuru, H. (1991). Endothelium-dependent relaxation induced by sodium fluoride in the rabbit ear artery. Experientia 47: 703-705.

Tsuru, H., Kohno, S. and Matsubayashi, H. (1990). Relaxation response of isolated canine veins to agents that act on the adenylate cyclase-cyclic AMP system : further investigation. Eur.J. Pharmacol. 191 : 447-455.

Waldman, S.A. and Murad, F. (1987). Cyclic GMP synthesis and function. Pharmacol. Rev. 39 : 163196.

Zeng, Y.Y., Benishin, C.G. and Pang, P.K.T. (1989). Guanine nucleotide binding proteins may 
modulate gating of calcium channels in vascular smooth muscle. II. Studies with guanosine 5'-( $\gamma)$ triphosphate. J. Pharmacol. Exp. Ther. $250: 343-351$. 